\title{
Doping mechanisms and electrical properties of bismuth tantalate fluorites
}

\begin{abstract}
Phase-pure bismuth tantalate fluorites were successfully prepared via conventional solid-state method at $900{ }^{\circ} \mathrm{C}$ in $24-48 \mathrm{~h}$. The subsolidus solution was proposed with the general formula of $\mathrm{Bi} 3+\mathrm{x}$ Ta1 $-\mathrm{x}$ O7-x $(0 \leq \mathrm{x} \leq 0.184)$, wherein the formation mechanism involved a one-toone replacement of Ta5+ cation by Bi3 + cation within $\sim 4.6 \mathrm{~mol} \%$ difference. These samples crystallised in a cubic symmetry, space group Fm-3 m with lattice constants, $a=b=c$ in the range $5.4477( \pm 0.0037)-5.4580( \pm 0.0039) \AA$. A slight increment in the unit cell was discernible with increasing $\mathrm{Bi} 2 \mathrm{O} 3$ content, and this may attribute to the incorporation of relatively larger $\mathrm{Bi} 3+$ cation in the host structure. The linear correlation between lattice parameter and composition variable showed that the Vegard's law was obeyed. Both TGA and DTA analyses showed $\mathrm{Bi} 3+\mathrm{x}$ Ta1-x $\mathrm{O} 7-\mathrm{x}$ samples to be thermally stable as neither phase transition nor weight loss was observed within $\sim 28-1000{ }^{\circ} \mathrm{C}$. The AC impedance study of $\mathrm{Bi} 3 \mathrm{TaO} 7$ samples was performed over the frequency range 5-13 $\mathrm{MHz}$. At intermediate temperatures, $\sim 350-850{ }^{\circ} \mathrm{C}, \mathrm{Bi} 3+\mathrm{x}$ Ta1 $-\mathrm{x}$ O7- $\mathrm{x}$ solid solution was a modest oxide ion conductor with conductivity, $\sim 10-6-10-3 \mathrm{~S} \mathrm{~cm}-1$; the activation energy was in the range $0.98-1.08 \mathrm{eV}$.
\end{abstract}

Keyword: $\mathrm{Bi} 3 \mathrm{TaO} 7$; $\mathrm{Bi} 3+x \mathrm{Ta} 1-\mathrm{x}$ O7-x; Electrical properties; Doping mechanisms 